\title{
FEMINISMO E MOVIMENTOS DE MULHERES NO CONTEXTO BRASILEIRO: A CONSTITUIÇÃO DE IDENTIDADES COLETIVAS E A BUSCA DE INCIDÊNCIA NAS POLÍTICAS PÚBLICAS
}

FEMINISM AND MOVEMENTS OF WOMEN IN THE BRAZILIAN CONTEXT:

THE CONSTITUTION OF COLLECTIVE IDENTITIES AND THE SEARCH FOR IMPACT ON PUBLIC POLICIES

\section{Mariana de Lima Campos ${ }^{1}$}

RECEBIDO EM:24/05/2017 | APROVADO EM: 01/07/2017

DOI: $10.5902 / 231717582731$

\section{RESUMO}

A atuação dos movimentos feministas abriu possibilidades e oportunidades para que mulheres, em sua multiplicidade de vivências, pudessem exercer o seu direito de participação política e social na busca por reconhecimento, igualdade e transformações sociais. Diante de cenários de oportunidades políticas favoráveis, as questões relativas aos direitos das mulheres no Brasil puderam ter outro status no discurso político e adentrar na agenda pública por meio do ativismo e ações de contestação, como também através da interação com Estado. Encampando diferentes lógicas de ação coletiva, mulheres impulsionadas pelo pensamento feminista se organizaram e se mobilizaram não só em manifestações e protestos, como também atuaram em instâncias participativas institucionalizadas, buscando incidir sobre a construção de políticas públicas perante suas demandas, lutas por direitos e mudanças sociais. O intuito deste artigo é apresentar, por meio de uma análise histórica, uma contextualização que possibilite evidenciar o protagonismo da atuação dos movimentos feministas na busca por direitos e demais agendas junto ao Estado e à sociedade, demarcando a importância política de suas lutas ao longo dos últimos anos no Brasil para que se fortalecesse a tendência da formulação de políticas mais inclusivas e relativas aos direitos das mulheres.

Palavras-chave: Feminismos; Movimentos feministas; Movimentos de mulheres; Políticas públicas

\footnotetext{
1 Mestra em Administração Pública pela Escola de Governo Prof. Paulo Neves de Carvalho - Fundação João Pinheiro (EG/FJP) com especialização lato sensu em Políticas Públicas e Gestão Governamental pela Universidade Federal Fluminense (UFF). Graduada em Ciências Sociais pela Universidade Federal de Viçosa (UFV). E-mail: marianalcampos@ gmail.com.
} 
FEMINISMO E MOVIMENTOS DE MULHERES NO CONTEXTO BRASILEIRO:

A CONSTITUIÇÃO DE IDENTIDADES COLETIVAS E A BUSCA DE INCIDÊNCIA NAS POLÍTICAS PÚBLICAS

\begin{abstract}
The action of the feminist movement opened possibilities and opportunities for women, in their multiplicity of experiences, could to exercise their right to political and social participation in the search for recognition, equality and social transformations. In the favorable political opportunity scenarios, the women's rights in Brazil won another status in political discourse and entered the public agenda through activism and contestation, as well as through interaction with the State. By means of different logics of collective action, women driven by feminist thinking, organized and mobilized themselves not only in demonstrations and protests, but also acted in institutionalized participatory instances, seeking to focus on the construction of public policies before their demands, struggles for rights and social transformations. The purpose of this article is to present through a historical analysis a contextualization that allows the understanding of the main forms of action of the feminist movement in the search for rights and other agendas with the State and society, highlighting the political importance of their struggles over of recent years in Brazil to strengthen the tendency of policy formulation more inclusive and relating to women's rights.
\end{abstract}

Keywords: Feminisms; Feminist movements; Movements of women; Public policy

\title{
1 Introdução
}

O feminismo pode ser considerado ao mesmo tempo uma teoria crítica em permanente construção sobre a sociedade e as desigualdades de gênero nela existentes, por meio de diferentes visões e posicionamentos políticos, e um movimento político que, confrontando os sistemas de dominação, exploração e opressão das mulheres, reúne um conjunto de discursos e práticas na luta por direitos e transformações no que se refere à igualdade e à justiça social. Essa linha teórica essencialmente política perpassou pelo longo processo de conscientização das mulheres e de suas lutas através da história pela redefinição de seu papel social, por direitos e pela equidade de gênero, no âmbito da sociedade civil e domínios institucionais.

A atuação dos movimentos feministas abriu possibilidades e oportunidades para que mulheres, em sua multiplicidade de vivências, pudessem exercer o seu direito de participação política e social na busca por reconhecimento, igualdade e transformações sociais. Isso porque, foi no caminho pavimentado pelos movimentos feministas, diante de cenários de oportunidades políticas favoráveis, que as questões relativas aos direitos das mulheres puderam ter outro status no discurso político e adentrar na agenda pública por meio do ativismo e ações de contestação, como também através da interação com Estado. Para o alcance de seus objetivos, em diferentes lógicas de ação coletiva, mulheres impulsionadas pelo pensamento feminista se organizaram e se mobilizaram não só em manifestações e protestos, como também atuaram em instâncias participativas institucionalizadas como conselhos, fóruns e conferências, buscando incidir sobre a construção de políticas públicas perante suas demandas e lutas por direitos e mudanças sociais. 
O intuito deste artigo é apresentar, a partir de uma revisão bibliográfica relativa aos avanços da inclusão da agenda dos feminismos no âmbito das políticas públicas, uma contextualização que possibilite evidenciar o protagonismo da atuação dos movimentos de mulheres e feministas pelo reconhecimento de suas identidades, direitos e demais agendas junto ao Estado e à sociedade, sobretudo a partir do processo de redemocratização do país na década de $1980^{2}$, demarcando a importância política de suas lutas até meados de 2015. Parte-se do pressuposto de que analisar a trajetória destes movimentos ao longo do tempo por meio de um método histórico, permiti-nos uma meIhor compreensão sobre sua influência na sociedade atual, tendo em vista seu papel para que o debate de gênero e sobre os direitos das mulheres pudessem constar na agenda pública, permitindo, consequentemente, o fortalecimento da tendência de formulação de políticas mais inclusivas.

Para tanto, além dessa introdução e considerações finais, parte-se de uma breve apresentação do feminismo enquanto um instrumento de reflexão sobre os mecanismos de reprodução das desigualdades de gênero e de mobilização social. Em seguida, apresenta-se o processo de constituição do feminismo enquanto movimento social de mulheres organizadas em busca de mudanças sociais, destacando-se o processo estabelecido de interação com o Estado no contexto brasileiro após o processo de redemocratização, que possibilitou o fortalecimento das questões de gênero e as oportunidades de desenvolvimento de políticas mais inclusivas e de reconhecimento das mulheres em sua diversidade.

\section{0 que motiva a ação coletiva? 0 feminismo enquanto um instrumento de reflexão e mobilização social}

Antes de analisarmos a trajetória dos movimentos de mulheres e feministas, suas formas de atuação e interação com o Estado no Brasil, é preciso compreender o porquê da mobilização de mulheres em torno de ideais em comum ${ }^{3}$. Quais as principais questões levantadas pelos movimentos feministas e seus significados? Quais motivações embasaram sua ação coletiva?

De uma forma geral, pode-se dizer que as ideias centrais do feminismo perpassam pelas noções de liberdade e igualdade, numa concepção de que a mulher enfrenta situações de desvantagem na sociedade pelo fato de ser muIher e que essa desvantagem pode e deve ser abolida (HEYWOOD, 2010). Para tanto, questiona e critica os padrões hierárquicos de poder estabelecidos nas

\footnotetext{
2 Ao darmos mais ênfase nas formas de ação coletiva ocorridas a partir da década de 1980, não queremos desconsiderar as mobilizações feministas existentes e conquistas das primeiras décadas do séc. XX. Para uma abordagem mais específica sobre os períodos precedentes ver, por exemplo, Teles (1993); Del Priori (1997); Pinto (2003); Bandeira; Melo (2010); Ogando (2012).

3 Cabe destacar que há uma diferenciação no uso das expressões "movimentos de mulheres" e "movimentos feministas". De acordo com Teles (1993), a primeira expressão é referente às ações organizadas de grupos que reivindicam direitos ou melhores condições de vida e, a segunda, está relacionada às ações de mulheres que objetivam o combate à discriminação e subalternidade das mulheres, tendo em vista o incentivo da sua liberdade e autonomia em um sentido geral.
} 
FEMINISMO E MOVIMENTOS DE MULHERES NO CONTEXTO BRASILEIRO:

A CONSTITUIÇÃO DE IDENTIDADES COLETIVAS E A BUSCA DE INCIDÊNCIA NAS POLÍTICAS PÚBLICAS

relações sociais entre homens e mulheres e suas consequentes repercussões nos âmbitos sociais, políticos, econômicos e culturais (SARDENBERG; COSTA, 1994). Vale destacar que nem todos os movimentos de mulheres são estruturados através do ideário feminista de reconhecimento e questionamento da situação e do papel da mulher na sociedade. Entretanto, como buscará se abordar nas páginas seguintes, a trajetória de luta dos movimentos feministas teve uma contribuição central para que mulheres, em sua diversidade de identidades e perspectivas, pudessem se mobilizar, se organizar e lutar por suas questões no âmbito da sociedade civil, como também em interação com o Estado.

A constituição de uma consciência que perpassa pela necessidade de que o papel social da mulher seja redefinido é um processo coletivo, que se dá no âmbito das relações entre homens e mulheres e se materializa nas práticas sociais (BANDEIRA; SIQUEIRA, 1989 apud SARDENBERG; COSTA, 1994). Isso nos remete à teoria da ação coletiva proposta por Melucci (2001)4, no sentido de que essa tomada de consciência se dá a partir do momento em que mulheres, ao compartilharem em redes de relacionamento experiências comuns diante de suas situações vivenciadas de opressão e subordinação em relação aos homens ${ }^{5}$, refletem sobre suas condições e papéis, reconhecem o que tem em comum, compartilham significados e vão construindo, assim, uma identidade coletiva ${ }^{6}$, que se fortalece também mediante o seu reconhecimento como atores coletivos.

A construção dessa identidade e o ideal de mudanças abrangentes no âmbito da sociedade e das relações sociais seriam, assim, importantes aspectos mobilizadores do envolvimento das mulheres na ação coletiva e de motivação para a luta social.

Não deixando de considerar a pluralidade dos movimentos feministas, tendo em vista que os mesmos se diferenciam por suas ideologias e atuações políticas7, por exemplo, é possível identificar e sinalizar uma plataforma de ação em que se evidenciam as críticas à separação entre as esferas do público e do privado e ao patriarcado, bem como discussões relativas a sexo e gênero e igualdade e diferença. Tais temas, desenvolvidos a seguir, sem a pretensão, no entanto, de se tecer uma análise exaustiva, subsidiam algumas das principais discussões que perpassaram e ainda perpassam os debates teóricos, as reivindicações e lutas sociais dos movimentos feministas. Compreendê-los nos permitirá entender por que se deu o início de mobilização de um movimento em oposição aos tradicionais

\footnotetext{
$4 \quad$ Melucci $(1989,2001)$ se destaca enquanto um dos autores da corrente europeia dos "novos movimentos sociais", constituída por diferentes esquemas interpretativos que enfatizam na interpretação das ações coletivas, de uma forma geral, a dimensão cultural das lutas sociais e os processos de identidade criados. Ver Gohn (1997) e Alonso (2009).

$5 \quad$ Para uma leitura mais abrangente sobre o conceito de opressão ver Iris Young (1990). A autora o relaciona às situações de desvantagens e injustiças assentadas em hábitos, normas, símbolos e práticas cotidianamente reproduzidas, que se constituem como um aspecto estrutural na vida de grupos minoritários. As situações de opressão normalmente perpassam, na concepção da autora, por cinco faces - não presentes de forma concomitante ou necessariamente em todos os grupos -, sendo elas a exploração, marginalização, impotência, imperialismo cultural e violência. No caso das mulheres pode-se dizer que opressão se assenta em práticas socialmente enraizadas e naturalizadas. É preciso considerar que as desvantagens e formas de opressão não se dão da mesma maneira para todas as mulheres, sua forma e intensidade se distinguem a depender da sociedade, período histórico, classe social, raça e etnia, por exemplo, implicando inclusive, na percepção que as mulheres podem ter das situações vividas de subordinação e consequentemente no seu ideal de transformação (SARDENBERG; COSTA, 1994).

6 A noção de identidade coletiva é utilizada neste artigo com base em Melucci $(1989,2001)$.

$7 \quad$ Pode-se considerar a existência de movimentos feministas, no plural, devido à diversidade de experiências de vida, perspectivas, identidades e pautas de diferentes grupos feministas.
} 
padrões socioculturais, práticas e arranjos institucionais existentes na sociedade.

Por ser um impedimento para o enfrentamento da opressão vivida pelas mulheres, as críticas à distinção entre a esfera pública e privada são cruciais ao pensamento feminista. Pressupõem de forma geral o questionamento da noção de que a política é uma atividade da arena da vida pública, em distinção à vida familiar e de relações pessoais, consideradas parte do âmbito privado (HEYWOOD, 2010). Neste sentido, os homens são vistos, sobretudo, ligados às ocupações da "esfera da vida econômica e política e responsáveis por elas, enquanto as muIheres seriam responsáveis pelas ocupações da esfera privada da domesticidade e reprodução" (OKIN, 2008, p.308), vistas como "naturalmente" inadequadas ao âmbito público. Okin (2008, p.320) destaca que devemos analisar esses espaços públicos considerando que são generificados, no sentido de que "foram construídos sob a afirmação da superioridade e da dominação masculinas e de que pressupõem a responsabilidade feminina pela esfera doméstica".

A linha de pensamento feminista pressupõe que a política é uma atividade presente em todos os grupos e espaços sociais, não apenas em assuntos relacionados a instituições políticas formais ou de debate público. Essa distinção acaba em isolar a política das relações de poder na vida cotidiana (MIGUEL; BIROLI, 2013). Entretanto, ela existe em todo e em qualquer conflito social. Este tipo específico de desigualdade persistiria na sociedade, exatamente pelo fato de que a divisão sexual do trabalho é por ela naturalizada, em que a mulher, "restrita" ao papel privado de esposa e mãe, estaria literalmente excluída da política e à margem da vida pública (HEYWOOD, 2010).

Desta percepção adveio a bandeira de luta "o pessoal é político", que está na raiz das críticas feministas à convencional dicotomia público/doméstico (OKIN, 2008), tornando políticas e públicas discussões tidas como do âmbito privado e individualizadas.

Nós queremos dizer, primeiramente, que o que acontece na vida pessoal, particularmente nas relações entre os sexos, não é imune em relação à dinâmica de poder, que tem tipicamente sido vista como a face distintiva do político. E nós também queremos dizer que nem o domínio da vida doméstica, pessoal, nem aquele da vida não-doméstica, econômica e política, podem ser interpretados isolados um do outro (OKIN, 2008, p.314).

O condicionamento de papéis masculinos e femininos na família ${ }^{8}$ e em todas as esferas da sociedade, a distribuição dos trabalhos domésticos, a política de conduta pessoal e sexual, a restrição do acesso das mulheres à esfera pública da educação, do trabalho e da vida política se constituíram como questionamentos do feminismo (HEYWOOD, 2010).

$8 \quad$ A partir de análises de conexões múltiplas entre os papéis domésticos das mulheres e a desigualdade, subordinação e segregação a que estão submetidas nos diferentes âmbitos sociais, a família se tornou central à política do feminismo e um foco da teoria feminista (OKIN, 2008, p.313). 
FEMINISMO E MOVIMENTOS DE MULHERES NO CONTEXTO BRASILEIRO:

A CONSTITUIÇÃO DE IDENTIDADES COLETIVAS E A BUSCA DE INCIDÊNCIA NAS POLÍTICAS PÚBLICAS

Seria necessária a redefinição das relações existentes no âmbito público e privado, garantindo a existência de justiça e que o acesso à qualquer posição, em ambas as esferas, não seja hierarquizado segundo diferenças sexuais. Isso porque, "não há sociedade justa na qual as relações na família sejam estruturalmente injustas", sendo preciso relações igualitárias em todas as esferas da vida (MIGUEL; BIROLI, 2013, p.17).

Para reforçar a ideia de que a sociedade é baseada em um sistema de desigualdade e opressão sexual, o conceito de patriarcado é utilizado pelo feminismo, por meio do qual é possível descrever um sistema de dominação e exploração das mulheres (SAFFIOTI, 2004). O patriarcado, em termos abrangentes, é comumente relacionado à "supremacia ou dominação masculina", que tem suas raízes na família (na figura do pai e/ou marido), mas que ordena e naturaliza relações de poder entre homens e mulheres em diferentes espaços, produzindo e reproduzindo desigualdades sociais, mantendo suas estruturas ao longo do tempo, mesmo que de formas diferenciadas. Neste sentido, se configura como uma estrutura social e um movimento histórico.

A categoria "mulher" utilizada pelo feminismo foi construída em meio às relações marcadas pelo patriarcado e pela dominação masculina (MIGUEL; BIROLI, 2013). Esta distinção é legitimada por arranjos assimétricos de poder construídos culturalmente a partir de uma diferenciação biológica entre homens e mulheres e de uma consequente relação de distinção estabelecida socialmente, baseada no gênero9.

Distinguir sexo e gênero, neste sentido, se mostra importante ${ }^{10}$. Os fatores biológicos não colocam em desvantagem ou determinam o destino social de mulheres. A capacidade de gerar filhos, por exemplo, não faz com que mães precisem aceitar responsabilidades maternas e abdicar de suas vidas para se dedicar inteiramente ao lar e a família. Essa noção é cultural, e não biológica. Essa linha de pensamento se refere à maneira pela qual a sociedade designa a homens e mulheres diferentes papéis, direitos e oportunidades de acordo com seu sexo biológico (SOARES, 2004), através de pressões, constrangimentos e expectativas sociais, os tornando sujeitos a valores histórico e socialmente construídos em relações de hierarquia e antagonismo.

Um dos principais objetivos do feminismo é evidenciar esta distinção, naturalizada e legitimada na sociedade principalmente pelo sistema de dominação patriarcal, recusando a construção hierárquica da relação entre masculino e feminino (SCOTT, 1989). Assim, a linha de pensamento feminista busca evidenciar a "especificidade da opressão das mulheres no contexto de culturas nas quais as distinções entre sexo e gênero são marcantes", contestando a naturalização da diferença sexual (HARAWAY, 2004, p.210)"1.

\footnotetext{
9 Cabe citar o debate existente entre o uso de ambos os conceitos, gênero e patriarcado, muito presente também no contexto brasileiro no início dos anos 1990. Ver Pateman (1993); Aguiar (2000).

10 Sexo se refere às diferenças naturais, biológicas, entre homens e mulheres. Por outro lado, gênero pode ser compreendido como uma institucionalização social das diferenças sexuais ou o elemento constitutivo de relações sociais baseado nas diferenças percebidas entre os sexos, sendo uma forma de significar as relações de poder (SCOTT, 1989).

11 Na concepção de Simone de Beauvoir, as assimetrias de gênero se dariam pelo fato de que as mulheres na sociedade não se pensavam enquanto "uma categoria una, como um sujeito coletivo capaz de agir historicamente", no sentido de rejeitar papéis tradicionais que lhes eram impostos (BEAUVIOIR, 1993,
} 
Estabelecer essa distinção foi um avanço no sentido de destacar as possibilidades de mudança social, pois algo socialmente construído pode ser desconstruído e transformado.

Essa noção é a base da perspectiva de gênero ${ }^{12}$, que desvela e busca modificar as desigualdades sociais, garantindo que as transformações se deem também do ponto de vista das discussões de gênero. $O$ intuito é alterar as relações de poder estabelecidas por mecanismos histórico-sociais, políticos e institucionais que mantém as mulheres em situações de submissão, opressão e injustiça, estendendo a elas oportunidades de acesso a direitos legítimos enquanto cidadãs, no sentido de sedimentar a igualdade.

O princípio da igualdade de direitos em relação aos homens é o que tradicionalmente esteve presente nos ideais do feminismo e nas ações coletivas dele derivadas, mesmo que posições igualitárias tivessem significados distintos para diferentes grupos. A crítica feminista redefine a própria noção de igualdade. Em suas diferentes vertentes, demanda por condições nas quais a igualdade seja efetiva, e as diferenças sejam reconhecidas de forma não hierarquizada (MIGUEL; BIROLI, 2013). Desta forma, o resultado político de sua ação coletiva em termos de igualdade permite que a diferença seja reconhecida e valorizada.

A noção de unidade em torno do significante "mulher" e da criação de uma identidade coletiva na linha de Melucci (2001), são formas de organizar uma percepção e interpretação de mundo por meio do questionamento de que há uma "distinção" entre homens e mulheres nos âmbitos público e privado, baseada em suas diferenças sexuais e que vincula a submissão da mulher na esfera doméstica à sua exclusão da vida pública (MIGUEL; BIROLI, 2013). Desta forma, algo que restringia as mulheres era utilizado como argumento e possibilidade de alcance de autonomia pelo feminismo, calcado em uma estratégia paradoxal de igualdade e de diferença em relação aos homens, seus privilégios e oportunidades, permitindo uma tomada de consciência perante injustiças sociais tidas como naturais em relações pautadas nas hierarquias de gênero.

Silva (2014) ao analisar a relação entre identidade e diferença, discute como a afirmação da identidade de diferentes grupos sociais e a marcação da diferença permeiam uma disputa mais ampla por outros recursos simbólicos e materiais da sociedade, estando imbricadas em relações de poder que implicam sempre em relações de "incluir" ou "excluir".

Os movimentos feministas, que se enquadram nas características das formas de ação coletiva que se ampliaram e se pluralizaram no contexto das transformações ocorridas na sociedade a partir dos anos 1960, os considerados

p. xx apud FERES JÚNIOR; POGREBINSCHI, 2010, p.94). Objetivo este que o movimento feminista passou a contemplar em suas ações

12 Destaca-se que o conceito gênero e a perspectiva de gênero se estabeleceram enquanto temas importantes no âmbito acadêmico (HEYWOOD, 2010, p.23). Segundo Okin (2008, p.311) citando Joan Scott, o termo gênero foi utilizado na área acadêmica de estudos sobre as mulheres no sentido de "transformar os paradigmas disciplinares", buscando um "reexame crítico das premissas e padrões dos trabalhos existentes" enquanto uma categoria importante da análise política e social. Sua descoberta possibilitou, sobretudo, a percepção das situações de desigualdade entre homens e mulheres na vida pública em geral. 
FEMINISMO E MOVIMENTOS DE MULHERES NO CONTEXTO BRASILEIRO:

A CONSTITUIÇÃO DE IDENTIDADES COLETIVAS E A BUSCA DE INCIDÊNCIA NAS POLÍTICAS PÚBLICAS

"novos movimentos sociais", não tiveram como intuito apenas buscar a igualdade de direitos, mas também o "direito de ser diferente". A diferença tornou-se assim, um objetivo cultural e político que embasou a mobilização de outros grupos e que busca influenciar a sociedade como todo (MELUCCI, 1989).

Entretanto, perante a reivindicação de mulheres situadas em segmentos específicos, percebe-se uma segunda forma de uso do significante "mulher", que rompe com seu conteúdo "uno". As duas perspectivas passaram a ser utilizadas na constituição de sujeitos políticos feministas e no debate por políticas de identidade nos movimentos feministas no Brasil: uma voltada para fora, "na relação do movimento em busca de igualdade de direitos", e a outra utilizada internamente, "na tensão entre diferença de segmentos e unidade" dentro do próprio movimento (ADRIÃO et al., 2011, p.665). Nessa perspectiva, o movimento feminista contemporâneo uniu valores do universalismo e da pluralidade/diferença, o que remete à considerada "nova" característica dos movimentos sociais. Nesse sentido, segundo Melucci (1989), o "êxito" dos movimentos feministas no campo político favoreceu sua segmentação. Como poderá ser visto mais adiante, a partir da segunda onda do feminismo, a tentativa de universalização em torno do "ser mulher" acabou levando também alguns grupos a negociar seus espaços revelando as diferenças vividas por mulheres em sua diversidade ${ }^{13}$.

De uma forma geral, pode-se considerar que as ações políticas pautadas pelo ideário feminista buscaram e buscam romper com as diferentes formas de opressão e subordinação das mulheres, afirmar sua autonomia enquanto sujeitos políticos e alcançar a efetividade de seus direitos em todas as esferas da vida. Enquanto uma teoria militante ${ }^{14}$, o feminismo se constitui como instrumento de reflexão sobre os mecanismos de reprodução das desigualdades de gênero, abrindo espaço para que as mulheres reflitam sobre suas condições, se mobilizem e se organizem coletivamente em direção às mudanças sociais. Diante disso, é possível compreender melhor os significados e os sentidos das ações dos movimentos feministas e como eles vão se relacionar com as demandas por transformação da condição das mulheres na sociedade e perante o Estado diante de contextos históricos específicos, tal qual veremos a seguir.

\footnotetext{
13 Há correntes feministas que aplicam a diferença não apenas à relação homens e mulheres, mas às próprias mulheres e sua multiplicidade de vivências numa sociedade marcada por diferentes clivagens, como é o caso do feminismo lésbico e o feminismo negro, por exemplo. Esta perspectiva difere-se ainda do chamado feminismo da diferença, o qual considera que a noção de igualdade entre homens e mulheres é equivocada, acreditando que a libertação significa "ser identificada como mulher" perante a percepção de que há diferenças significativas entre os sexos, as quais possuem importância política e social. Para esses grupos, especificamente, seria preciso que as mulheres reconheçam e celebrem as características singulares do sexo feminino. Dentre todas as vertentes existentes, talvez possa se considerar, assim como Heywood (2010), que uma variedade tão grande de preocupações e interesses possa ser mais uma indicação da força do feminismo do que da fragilidade do movimento.

$14 \quad$ Segundo Siliprandi (2015, p.37-38), o feminismo pode ser considerado uma teoria crítica e movimento social. Enquanto teoria crítica evidencia como a realidade social se estrutura através de um sistema sexo-gênero e de relações hierárquicas, expressos na dominação das mulheres pelos homens, se constituindo enquanto uma teoria reflexiva e emancipatória que analisa e questiona o passado, "jogando luzes" sobre tais aspectos da ordem social que não seriam visíveis sob outra perspectiva. Enquanto movimento social, o feminismo se mostra como um instrumento para mobilização social, abrindo espaço para que grupos oprimidos (no caso, as mulheres) se organizem em prol de mudanças sociais. Nos termos de Miguel e Biroli (2013, p.07) enquanto corrente intelectual, "o feminismo combina a militância pela igualdade de gênero com a investigação relativa às causas e os mecanismos de reprodução da dominação masculina".
} 


\section{Repertórios de ação e interação com o Estado: a trajetória dos movimentos feministas e a constituição de uma agenda relacionada à questão de gênero}

Como dito, os movimentos feministas estão dentre os diferentes movimentos sociais que inscreveram suas demandas na agenda contemporânea (ALONSO, 2009). Destacaram-se ao questionar padrões socioculturais pautados na opressão da mulher e demandar alterações nas normas de gênero no âmbito da sociedade civil por meio de um discurso político de identidade, bem como almejar mudanças nas instituições políticas e econômicas, através de uma múltipla lógica de ação coletiva.

A atuação dos movimentos feministas pode ser dividida em "fases" ou "ondas"15. A considerada primeira onda do feminismo se deu partir das últimas décadas do séc.XIX, em que as iniciativas existentes e vozes que ecoavam ainda não tinham a especificidade de questionar o papel social da mulher. As iniciativas partiam de uma maneira geral, de algumas mulheres de classes médias e altas, que buscavam a extensão dos princípios igualitários de cidadania.

Naquele período, as manifestações públicas que começaram a surgir em busca da igualdade entre homens e mulheres, principalmente na Inglaterra, se referiam à conquista de direitos legais e políticos como o acesso à educação ${ }^{16}$, ao mercado de trabalho e ao direito a votar ${ }^{17}$. No Brasil, a primeira onda do feminismo também se manifestou principalmente por meio da luta pelo voto (PINTO, 2010).

A partir do período de 1930, essas primeiras iniciativas perderam força na Europa e nos Estados Unidos, como também no Brasil. Na década de 1960, no contexto de emergência dos considerados novos movimentos sociais, o feminismo reaparece com mais força frente a reflexões acerca do androcentris$\mathrm{mo}^{18}$ da sociedade capitalista e do papel da mulher na sociedade ${ }^{19}$, permitindo que as desigualdades de gênero existentes nos diferentes âmbitos sociais passassem a ser explicitadas de forma mais enfática. Essas desigualdades eram questionadas por grupos autodenominados como movimentos de libertação

\footnotetext{
$15 \quad$ Cabe ressaltar a existência de críticas em relação ao uso desta metáfora para se pensar o movimento feminista de uma forma geral. Uma delas é que a ideia de "onda" pode gerar uma percepção linear das lutas feministas no tempo e no espaço, uma lógica "etapista" ou mesmo evolucionária, como se as demandas fossem progredindo e sendo resolvidas à medida que se passa de uma onda para outra. Tais percepcões são equivocadas e precisam ser ponderadas, tendo em vista que há alguns temas permanentes e atuais que atravessam o movimento feminista desde suas origens, tal como a violência contra as mulheres ou a sub-representação das mulheres nos espaços de poder, por exemplo, questões não equacionadas ainda nos dias atuais.

16 Um dos argumentos utilizados era o de que por meio da educação, por exemplo, as mulheres poderiam ter acesso à razão, no sentido de desenvolver uma consciência mais crítica de sua condição e assim, buscar seus próprios interesses, participar da vida pública e das profissões até então abertas aos homens (WOLLSTONECRAFT, 1972, p.262 apud FERES JÚNIOR; POGREBINSCHI, 2010, p.94).

17 A conquista do direito ao voto no Reino Unido se deu em 1918. No Brasil a conquista se deu em 1932 com a promulgação do Novo Código Eleitoral brasileiro. A Federação Brasileira pelo Progresso Feminino, a qual teve Bertha Lutz como uma de suas fundadoras, teve um papel fundamental de pressão frente ao Senado para aprovação de um projeto de lei que daria o direito de voto às mulheres (PINTO, 2010), numa demonstração de ação coletiva ofensiva objetivando uma inclusão em termos igualitários na estrutura política e institucional da sociedade.

$18 \quad O$ androcentrismo está relacionado às sociedades que privilegiam a perspectiva masculina e inferiorizam ou invisibilizam a contribuição das mulheres.

19 Segundo Céli Pinto (2010), a obra "O segundo sexo" de Simone de Beauvoir, publicado em 1949, marcou as mulheres ao longo desses trinta anos, sendo central para a emergência da nova onda do feminismo. O livro evidenciava e relacionava a opressão das mulheres a processos sociais e históricos.
} 
FEMINISMO E MOVIMENTOS DE MULHERES NO CONTEXTO BRASILEIRO:

A CONSTITUIÇÃO DE IDENTIDADES COLETIVAS E A BUSCA DE INCIDÊNCIA NAS POLÍTICAS PÚBLICAS

das mulheres, que passaram posteriormente a se denominar como feministas, constituindo de uma maneira geral a segunda onda do movimento, enquanto um dos novos movimentos sociais que se consolidaram desafiando as estruturas normatizadoras da sociedade ${ }^{20}$.

Esta nova onda reconheceu que a conquista de direitos políticos e legais não resolvera por si só a "questão das mulheres", chamando a atenção para diferentes aspectos pessoais, psicológicos e sexuais da opressão feminina (HEYWOOD, 2010) na luta por uma nova forma de relacionamento entre homens e mulheres, politizando "o pessoal" frente a uma concepção de liberdade e autonomia. Para tanto, enfatizava a necessidade de um processo mais abrangente de mudança social. Não buscava apenas o ideal de emancipação política para a igualdade social como a geração anterior, mas, enfatizava, sobretudo, a busca por transformações culturais e o reconhecimento ${ }^{21}$ das especificidades do ser mulher em uma sociedade que privilegia atitudes e práticas masculinas.

Como apontado anteriormente, a construção do feminismo enquanto um movimento social tinha a solidariedade entre as mulheres como base organizacional que permitia a iminência de uma identidade coletiva em comum, constituída em torno da desvalorização da mulher, podendo ser considerada como um elemento central para a estruturação do movimento (PINTAGUY, 2011).

Sua atuação pode ser considerada a partir da perspectiva de busca por direitos civis e políticos em um repertório de ação 22 que se ampliava em um discurso comunicativo político de identidade e influência, visando desconstruir, nos diferentes âmbitos da vida cotidiana, as desigualdades históricas e padrões enraizados de opressão e desvalorização do feminino, moldados por práticas culturais e sociais, naturalizados por diferentes valores e crenças.

Na Europa e nos Estados Unidos, o cenário político daquele período foi propício para o surgimento de movimentos libertários, possibilitando oportunidades favoráveis aos que lutavam por causas identitárias. O momento ditatorial fez com que o Brasil passasse por uma dinâmica diversa (PINTO, 2010). Foi num contexto em que movimentos sociais encontravam limites para a expressão de reivindicações na arena pública diante de uma estrutura de oportunidade política com constrangimentos, num cenário conservador de opressão, repressão e desvalorização da cidadania, que as primeiras manifestações feministas aconteceram no país ${ }^{23}$.

\footnotetext{
20 A emergência da segunda onda do feminismo no contexto norte americano e europeu coincidiu com a "prosperidade" do Estado de bem estar social. O imaginário social democrata enfatizava a redistribuição entre as classes, mas repousava sobre uma série de exclusões de gênero e raça. As ações coletivas da década de 1960 se deram como parte de um esforço maior para transformar este imaginário político economicista e questionar as características centrais da modernidade capitalista que a social democracia tinha naturalizado até então (FRASER, 2007, p.293-295)

21 Cabe ressaltar que o tema do reconhecimento é abordado por diferentes autores como Charles Taylor (1992), Axel Honneth (2003), Iris Young (1990) e Nancy Fraser (1997, 2007), que de maneiras diferentes propõem teorias da justiça relacionadas às lutas por reconhecimento de identidades. Nesse sentido, ver Garcês (2014), a qual postula que mesmo não voltadas propriamente para explicações sobre as formas e motivações das ações coletivas, há uma possível contribuição das teorias do reconhecimento ao campo de análise dos movimentos sociais especialmente a dos novos movimentos sociais, dentre os quais destaca a centralidade concedida tanto às questões de identidade coletiva, quanto ao conceito de conflito como uma expressão de mudanças sociais.

22 Os conceitos de repertório de ação e estrutura de oportunidade política são utilizados com base nos autores Tilly (1978), Tarrow (1983) e McAdamm (1982) precursores da teoria do processo político inscrita na tradição norte americana de abordagens sobre movimentos sociais. Ver Gohn (1997); Alonso (2009).

23 Segundo Barsted (1994, p. 40), era perceptível uma dupla identidade dos movimentos de mu-
} 
No contexto mundial, as propostas e recomendações para melhoria nas condições de vida das mulheres levou à realização da I Conferência Internacional da Mulher, realizada no México, em $1975^{24}$ pelas Nações Unidas e de outras conferências e acordos firmados ao longo dos anos seguintes ${ }^{25}$, possibilitando em nível internacional a repercussão de uma temática de gênero, tendo como pontos básicos a denúncia da discriminação das mulheres e a luta pela igualdade de direitos (BARSTED, 1994).

Já no contexto brasileiro, apenas com a abertura democrática dos anos 1980 é que as questões feministas puderam ganhar de fato espaço de reivindicação, num período marcado pela efervescência de lutas sociais que perpassavam por diferentes temas e pela busca por reformas constitucionais, participação política e transformações institucionais. Abriu-se possibilidade para que a luta pelos direitos das mulheres pudesse transitar pelo plano normativo e jurídico no país, considerando que os movimentos feministas tiveram contribuição central para a "inclusão da questão de gênero na agenda pública como uma das desigualdades a serem superadas por um regime democrático" (FARAH, 2004a, p.51).

Deu-se início ao período considerado por Céli Pinto (2003) como a terceira onda do feminismo brasileiro, difuso em diferentes arenas da sociedade e que enfatizava além das possibilidades de acesso à política institucional, a discussão das diferenças entre as mulheres e suas novas formas de organização. Foi nesse momento que os movimentos feministas passaram por um processo de diversificação. Os grupos passaram a enfatizar a necessidade do reconhecimento da diferença ao expressarem suas reivindicações, assentados em um mesmo ideal de transformação, capaz de impulsionar a luta pela liberdade, igualdade e autonomia para todas as mulheres, o que se constituiu como um elemento central para o aprofundamento da democracia, e que incluiu o combate à opressão e exploração das mulheres (SILVA; CAMURÇA, 2010) ${ }^{26}$.

Apesar de o cenário mundial demonstrar uma relação direta dos movimentos de mulheres e feministas aos avanços nas discussões relacionadas à concretização de iniciativas institucionais de promoção dos direitos da mulher, no Brasil, até a década de 1980, não havia perspectivas claras de relação com o Estado no projeto de transformação feminista. As possibilidades de reivindicação ao nível institucional e de se avançar em termos de "política feminista" começaram a surgir a partir de 1983, principalmente através da criação dos primeiros Conse-

\footnotetext{
Iheres em geral no Brasil, de um lado sendo parte do movimento contra a ditadura e a favor do restabelecimento democrático, e de outro, apresentando-se como um ator social novo na luta pelo reconhecimento da condição da mulher enquanto problemática social.

24 Em 1975 foi promovida pelas Nações Unidas a "década da mulher", possibilitando em nível internacional a repercussão de uma temática de gênero tendo como pontos básicos a denúncia da discriminação das mulheres e a luta pela igualdade de direitos (BARSTED, 1994, p.39).

$25 \quad$ Outro exemplo importante é a Conferência Mundial sobre as Mulheres, realizada em Nairóbi no ano de 1985 e a Conferência Mundial dos Direitos Humanos, realizada mais tarde pela ONU, em Viena no ano de 1993, que reconheceu que a proteção e promoção dos direitos das mulheres deveriam ser aspectos prioritários para a comunidade internacional.

26 Neste período os feminismos se pluralizaram perante a crescente visibilidade e força de outras identidades que emergiram, sobretudo, perante a concepção de impossibilidade de que a condição feminina pudesse ser universalizada como uma única forma de opressão vivida por todas as mulheres (SILIPRANDI, 2015). São exemplos o feminismo negro, lésbico, popular, organização de mulheres sindicalistas, rurais, que buscavam o reconhecimento de sua identidade, formas de inclusão, participação e interação com diferentes instituições políticas e sociais.
} 
FEMINISMO E MOVIMENTOS DE MULHERES NO CONTEXTO BRASILEIRO:

A CONSTITUIÇÃO DE IDENTIDADES COLETIVAS E A BUSCA DE INCIDÊNCIA NAS POLÍTICAS PÚBLICAS

Ihos dos Direitos da Mulher, nacional, estaduais e municipais ${ }^{27}$ (TIMOTEO, 2013).

A relação desses grupos com o Estado passou por transformações, sobretudo devido ao surgimento de canais institucionais de participação no processo de redemocratização do país (SARTI, 1988), momento o qual começou a se estabelecer enquanto uma oportunidade política favorável à ação dos movimentos sociais em busca de influenciar o âmbito das políticas públicas. Naquele momento é que a parcela significativa dos movimentos de mulheres se propôs a buscar uma interlocução com o governo enquanto sociedade civil, e também a "penetrar nos aparelhos do Estado" (PITANGUY, 2002; BARSTED, 1994), apontando para a modificação de um repertório de interação Estado-sociedade ${ }^{28}$.

A atuação do feminismo em nível institucional e na sua relação com o Estado foi um processo que gerou divergências dentro do próprio movimento (FARAH, 2004a; PITANGUY, 2002, BARSTED, 1994; SCHUMAHER; VARGAS, 1993). Parte das militantes se somou ao quadro político institucional que vinha se desenhando no país. Entretanto, houve aquelas que se mantiveram contrárias à incorporação no Estado, temendo-se, principalmente, eventual cooptação do movimento (PITANGUY, 2002), a descaracterização de suas reivindicações e que se colocasse em risco aquilo que se configurava como a sua unidade mínima, ou seja, sua autonomia (SCHUMAHER; VARGAS, 1993) ${ }^{29}$. Assim, aquelas que eram críticas à aproximação das esferas estatais se mantiveram "fora da institucionalidade", fortalecendo as organizações e movimentos de mulheres no âmbito da sociedade civil que, dentre suas diferentes formas de ação, exerceram também o papel de pressionar e dialogar com governos para a permanência de suas pautas e demandas na agenda pública, como também encamparam programas de gênero em áreas como saúde, combate à violência, educação, geração de renda e organização de mulheres (FARAH, 2004a, p.53).

Destaca-se assim, uma multidimensionalidade dos repertórios de ação coletiva feministas e o potencial de sua atuação política.

Apesar da resistência por parte de algumas militantes, não havia como deixar de reconhecer a capacidade do Estado em influenciar a sociedade como um todo por meio das "leis, políticas sociais e econômicas, ações de bem estar, mecanismos reguladores da cultura e comunicação pública, e, portanto, como um aliado fundamental na transformação da condição feminina" (MOLYNEUX, 2003 apud TIMOTEO, 2013, p.99). A ideia de ignorá-lo ou rejeitá -lo como interlocutor foi sendo complementada então pela compreensão de que a cidadania se concretizaria no diálogo entre Estado e sociedade, tendo como cenário político a democracia (BARSTED, 1994).

\footnotetext{
27 Os Conselhos dos Direitos da Mulher envolvem a participação da sociedade civil na discussão, formulação e promoção de políticas, medidas e/ou ações com vistas à garantia dos direitos da mulher. São exemplos das instituições participativas (AVRITZER, 2008) que permitiram uma interação entre movimentos sociais e o Estado perante a possibilidade de participação institucional.

28 A noção de repertório de interação Estado-sociedade é abordada nesse artigo de acordo com a linha do pensamento proposto por Abers, Serafim e Tatagiba (2014).

29 Isso ocorria também em compasso com outros movimentos sociais no país e mesmo na América Latina, cuja atuação se marcava por uma recusa à institucionalidade no Estado associada a seus ideais de autonomia, mas também aos contextos de governos autoritários. Em meados dos anos 80, nos contextos de redemocratização, contudo, a disposição dos movimentos sociais altera-se, encampando possibilidades de uma atuação em espaços institucionalizados (TEIXEIRA, 2001).
} 
Em um contexto de resistência e luta constante contra o sistema patriarcal, coube aos movimentos feministas, enquanto movimentos sociais organizados, pressionar, fiscalizar e buscar influenciar o aparelho estatal para a definição das metas sociais e políticas públicas associadas à busca pela equidade de gênero (TIMOTEO, 2013). Tal qual nos aponta a abordagem norte americana sobre movimentos sociais, mais precisamente a teoria do processo político, os atores constantemente modificam seu repertório de ação coletiva combinando diferentes formas e estratégias de alcançar seus objetivos. Nesta perspectiva, buscando uma atuação também em espaços institucionais, se deu a atuação de parte dos movimentos feministas nos conselhos ${ }^{30}$. Em 1985, o então criado Conselho Nacional dos Direitos da Mulher (CNDM) ${ }^{31}$, enquanto um canal institucional de participação da sociedade civil, para formulação e monitoramento de políticas públicas, constituiu-se como um marco histórico, "por ser a primeira vez que, no governo federal, se reconheceu a existência da desigualdade sexual e da importância da atuação das mulheres no Brasili32" (SARTI, 1988, p.46).

Assim, pode-se afirmar que o período de democratização e as novas formas de interação com o Estado possibilitaram que novas pautas e demandas entrassem na agenda pública brasileira. Durante a Assembleia Nacional Constituinte, esses grupos estiveram organizados em todo o país para influenciar a elaboração da nova Constituição e ampliação da cidadania feminina ${ }^{33}$.

Segundo Farah (2004a), o processo de democratização e as oportunidades abertas para o desenvolvimento de políticas mais inclusivas possibilitaram que a tendência de formulação de políticas públicas começasse a se fortalecer neste âmbito, se constituindo como um espaço privilegiado na luta pela superação da desigualdade entre homens e mulheres na sociedade brasileira. Somado a esse contexto, a autora ressalta também a influência no cenário nacional da luta do feminismo pela incorporação da perspectiva de gênero nas políticas públicas durante os diferentes encontros e conferências internacio-

\footnotetext{
$30 \quad$ Segundo Barsted (1994, p. 45), participavam dos Conselhos estaduais e municipais já criados no país e do Conselho Nacional, mulheres organicamente vinculadas ao movimento feminista, muitas oriundas do espaço acadêmico. Estes órgãos trabalhavam em colaboração com movimentos autônomos de mulheres e ONGs dedicados à condição feminina, possibilitando a participação de um movimento social no interior do Estado sem a ele estar subordinado política ou ideologicamente.

$31 \quad O$ Conselho Nacional dos Direitos das Mulheres (CNDM) foi criado por meio da Lei $n^{\circ} 7.353 / 85$ vinculado ao Ministério da Justiça, tendo seu desenho institucional alterado ao longo dos anos. Em 2003 passou a integrar a estrutura básica da criada Secretaria Especial de Políticas para as Mulheres da Presidência da República (SPM/PR). Enquanto órgão colegiado de natureza consultiva e deliberativa, tem como finalidade formular e propor diretrizes para a ação governamental voltada à promoção dos direitos das mulheres e atuar no controle das políticas de igualdade de gênero, tendo em sua composição representantes da sociedade civil/movimentos sociais e do governo. Disponível em: <www.spm.gov.br> Acesso em 18 jul. 2016. 32 O CNDM, do ponto de vista internacional, se insere no contexto das recomendações da Conferência Internacional de Mulheres realizada em Nairóbi (1985), para que os governos nacionais passassem a empreender esforços na criação de mecanismos governamentais voltados para a condição da mulher, sendo um dos primeiros órgãos de promoção aos direitos da mulher criados na América Latina (PITANGUY, 2002, p.09).

33 Diante das oportunidades políticas existentes com a realização da Assembleia Nacional Constituinte, o CNDM, os conselhos estaduais e municipais de direitos das mulheres, o movimento feminista e outras organizações de mulheres no país, conduziram a campanha nacional "Constituinte pra valer tem que ter palavra de mulher", integrando propostas regionais na defesa da construção de uma legislação mais igualitária, sistematizadas na "Carta das Mulheres aos Constituintes", em um trabalho de advogacy com o intuito de influenciar o sistema político. O uso da mídia também foi utilizado como recurso para sensibilizar a sociedade sobre as questões relativas aos direitos da mulher com a produção de frames, na linha de Snow e Benford (1992 apud GOHN, 1997). Este esforço consensual com estratégias conjuntas influenciou para que cerca de $80 \%$ das demandas e reivindicações fossem incluídas no texto constitucional de 1988 (PITANGUY, 2002). Esta mobilização permitiu um fortalecimento do movimento de mulheres no país.
} 
FEMINISMO E MOVIMENTOS DE MULHERES NO CONTEXTO BRASILEIRO:

A CONSTITUIÇÃO DE IDENTIDADES COLETIVAS E A BUSCA DE INCIDÊNCIA NAS POLÍTICAS PÚBLICAS

nais que impulsionavam a proposta de concretização de uma política mundial de promoção igualdade e oportunidades para as mulheres que assegurasse "respostas às demandas de forma mais eficaz nas políticas, nas ações e nos programas governamentais".

Durante a Conferência de Beijing (1995), tal estratégia foi designada como gender mainstreaming e reconhecida como transversalidade de gênero, garantindo a incorporação da melhora do status das mulheres em todas as dimensões da sociedade, com repercussões nas esferas jurídicas e administrativas. Desta forma, significava para os governos "um impacto vinculante a ser assimilado pelas políticas propostas pelo Estado e desenvolvidas em cada área governamental", enquanto uma estratégia básica de promoção da equidade (BANDEIRA; ALMEIDA, 2013, p.40).

De acordo com Farah (2004a), com base em toda a trajetória dos movimentos de mulheres no Brasil, somada também à plataforma de ação das diferentes mobilizações internacionais, constituiu-se no Brasil uma agenda atual relacionada à questão de gênero, com diretrizes que perpassaram questões relacionadas à saúde, violência, direitos de meninas e adolescentes, geração de emprego e renda, combate à pobreza, educação, trabalho, infraestrutura urbana e habitação, questão agrária, incorporação da perspectiva de gênero

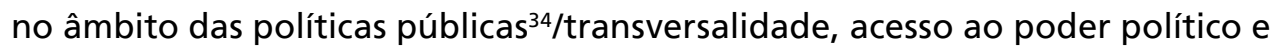
empoderamento, por exemplo.

A entrada de mulheres pautadas pelo ideário feminista no Estado fez com que reivindicassem mudanças nas instituições, a criação de novos serviços e outros olhares para as novas demandas colocadas pela sociedade, permitindo uma interlocução mais efetiva no âmbito das políticas públicas (DINIZ, 2006) e uma tendência da introdução da questão de gênero em áreas tradicionalmente desvinculadas desta questão (BARSTED, 1994).

Pitanguy (2002), entretanto, ressalta a existência de desafios na consolidação das conquistas alcançadas em termos de agenda dos direitos das muIheres e de avanços em sua implementação, perante a conjuntura da década de 1990 e às ondas conservadoras dentro e fora do governo. Tal contexto pode ser exemplificado por um fato descrito por Barsted (1994, p.46). Segundo a autora, de 1985 a 1989, o CNDM foi o órgão de articulação nacional entre movimentos de mulheres, de ONGs e instâncias governamentais, representando a convivência democrática entre Estado e nação, visto que pertencia ao governo, mas era dirigido por representantes de movimentos sociais. Esse fato gerou reações de grupos conservadores, fazendo com que em 1989, perante a conjuntura internacional de ajustes econômicos, com efeitos recessivos no que se refere à alocação de recursos em setores sociais, o CNDM perdesse

34 É preciso enfatizar que políticas públicas dirigidas às mulheres podem não contemplar necessariamente a perspectiva de gênero, ou seja, nem todas podem ter uma perspectiva relacional e crítica das desigualdades entre e intra grupos de homens e mulheres com o intuito de promover a igualdade de gênero, podendo existir programas e ações que focalizem mulheres, mas não priorizem sua autonomia ou reforcem suas condições de subordinação e a ideologia patriarcal, por exemplo (BANDEIRA; ALMEIDA, 2013; FARAH, 2004a). 
a autonomia conquistada em sua criação, tendo alterações em sua estrutura técnica, administrativa e orçamentária, o que provocou seu esvaziamento e desarticulação, demonstrando na percepção da autora, "as possibilidades e os limites do processo brasileiro de redemocratização".

Entretanto, a atuação dos movimentos de mulheres por todo o país continuava. Cresceram relativamente o número de organizações de mulheres em diálogo com movimentos e agências internacionais, centro de estudos em universidades e organismos governamentais em alguns estados e municípios (BARSTED, 1994), o que permitiu que a consciência feminista continuasse adentrando na dimensão das relações sociais.

No âmbito do Governo Federal, foi criada, em 2002, a Secretaria de Estado de Direitos da Mulher (SEDIM), ligada à Secretaria de Estado de Direitos Humanos, vinculada ao Ministério da Justiça, possivelmente a partir da trajetória de pressões e atuação dos movimentos de mulheres na sociedade brasileira, abrindo possibilidade para que novamente a questão da cidadania da mulher e das políticas públicas de gênero no Brasil pudesse constar na dinâmica das disputas e alianças no âmbito do governo, tendo o CNDM no cenário político como órgão deliberativo (PITANGUY, 2002).

Já no ano seguinte, no primeiro mandato do presidente Luís Inácio Lula da Silva, foi instituída a Secretaria Especial de Políticas para as Mulheres (SPM -PR), subordinada diretamente à Presidência da República com caráter ministerial. Em sua composição, a SPM-PR contou com três secretarias temáticas: a Secretaria de Políticas do Trabalho e Autonomia Econômica das Mulheres (SAE); a Secretaria de Articulação Institucional e Ações Temáticas (SAIAT) e a Secretaria de Enfrentamento à Violência contra as Mulheres (SEV $)^{35}$, assumindo, sobremaneira, uma importância ao avanço nas respostas do Estado frente às desigualdades de gênero no Brasil nos anos posteriores.

Ressalta-se ainda, uma ampla participação institucional das mulheres no país a partir deste período por meio da realização das primeiras Conferências de Políticas para as Mulheres ${ }^{36}$, convocadas pela SPM-PR em conjunto com o CNDM, que embasaram a construção coletiva entre governo e sociedade civil de três Planos Nacionais de Políticas para as Mulheres que sistematizam as diretrizes e ações de promoção à igualdade de gênero vigentes até então no país (BRASIL, 2013).

\footnotetext{
35 A Secretaria de Políticas do Trabalho e Autonomia Econômica das Mulheres mantinha três coordenações: Coordenação Geral de Autonomia Econômica; Coordenação Geral de Estudos e Pesquisas e a Coordenação Geral de Direitos do Trabalho das Mulheres. A Secretaria de Articulação Institucional e Ações Temáticas mantinha a Coordenação de convênios e assessoria temática, a Coordenação de Relações de Poder e Participação Política e a Coordenação Geral de Programas e Ações de Educação e Cultura. A Secretaria de Enfrentamento à Violência contra a mulher mantinha três coordenações: Coordenação Geral de Fortalecimento da Rede de Atendimento; Coordenação da Central de Atendimento à Mulher e a Coordenação de Ações Preventivas e Garantia de Direitos.

36 A I, II, III e IV Conferências Nacionais de Políticas para as Mulheres foram realizadas nos anos de 2004, 2007, 2011 e 2016, respectivamente. Destaca-se que as conferências são importantes espaços institucionais para a tematizacão de questões sociais e difusão de ideias, se constituindo enquanto uma base para a formulação de políticas públicas em diálogo com representantes da sociedade civil organizada, incluindo-se aí os movimentos sociais. Para uma melhor compreensão sobre a importância das conferências nacionais de políticas para as mulheres na conformação de novas relações entre a sociedade civil e o Estado ver Pinheiro e Ogando (2012)
} 
FEMINISMO E MOVIMENTOS DE MULHERES NO CONTEXTO BRASILEIRO:

A CONSTITUIÇÃO DE IDENTIDADES COLETIVAS E A BUSCA DE INCIDÊNCIA NAS POLÍTICAS PÚBLICAS

Matos (2016), em um estudo recente e ainda parcial, demonstra, analisando iniciativas de políticas relacionadas a gênero promovidas pelo poder público desde a redemocratização do país até o ano de 2015, como as iniciativas estatais relacionadas a gênero e sexualidade implantadas de 2003 a 2015 ("Era PT") aumentaram em escala e magnitude, com expressividade das políticas para as mulheres ${ }^{37}$. A autora atribui a essa fase, a existência de "contornos de aprofundamento dos processos popular-participativos que culminaram na elaboração de uma significativa rede de políticas públicas de reconhecimento, antidiscriminatórias e de inclusão democrática" de grupos considerados subalternos, demonstrando como os governos deste período se deixaram permear mais do que nos períodos anteriores (1988-2002) pela agenda reivindicatória dos movimentos de mulheres e feministas, transformando demandas em pautas efetivas de ação governamental.

A atuação da SPM-PR permitiu, desta forma, uma mudança na relação dos movimentos feministas com o Estado brasileiro (PINHEIRO; OGANDO, 2012). Pode-se dizer que diante de um contexto de oportunidades políticas favoráveis, abriram-se possibilidades de canais de expressão e participação institucional, permitindo a esses movimentos canalizar demandas e colocando em evidência um repertório de ações mais institucionalizadas.

Matos $(2010,2014)$ propõe a possibilidade de que pensemos em uma nova fase para os movimentos feministas, ou uma "quarta" onda. Essa fase mais recente indica uma análise não apenas pelas agendas ou formas organizativas dos movimentos, mas também por perspectivas de aproximação e atuação dentro do Estado, perante a abertura de certas possibilidades de interação, utilizadas enquanto estratégias de ação para o alcance de uma sociedade mais igualitária e equânime. Segundo a autora, a institucionalização de demandas dos movimentos de mulheres e feministas através de políticas públicas para mulheres, com recortes raciais, sexuais e geracionais, a criação de organismos de políticas para as mulheres, a busca por mais poder político, a criação de Ongs e redes feministas relacionadas à agenda internacional das mulheres e um novo frame para atuação do feminismo numa perspectiva transnacional, são exemplos que ajudam a entender a conformação dessa nova onda ${ }^{38}$.

\footnotetext{
37 O estudo demonstra que, no período de 1988 a 2002, a agenda setorial prioritária de políticas públicas esteve associada a áreas como Saúde, Direitos e Justiça, Trabalho e Previdência, referentes a pautas universais. Já no período de 2003 a 2015, áreas setoriais como Participação e Representação, Trabalho e Previdência e Violência contra a Mulher, por exemplo, obtiveram aumento expressivo, demonstrando prioridades da agenda governamental do período alinhadas às propostas programáticas do Partido dos Trabalhadores (MATOS, 2016).

38 Para Matos (2014), o feminismo, em parte significativa dos países da América Latina, se transversalizou por diferentes níveis de governo, perpassando por diversas arenas políticas nacionais e internacionais, como também se estendeu horizontalmente, ao longo de diferentes classes sociais, de movimentos que se mobilizam pela livre expressão de experiências sexuais, de comunidades étnico raciais, rurais, além de múltiplos espaços sociais e culturais, inclusive em movimentos sociais paralelos, que alargam a concepção de direitos humanos e ressignificam as lutas por mais justiça a partir da perspectiva feminista (MATOS, 2014, p.09)
} 


\section{Considerações finais}

Tendo em vista o exposto, pode-se dizer que o feminismo enquanto um ideário de transformação foi responsável por significativas mudanças ocorridas na sociedade em seus diferentes âmbitos e sistemas institucionais. Ao evidenciar as diversas formas de opressão e discriminação pautadas nas hierarquias de poder e de gênero, permitiu uma tomada de consciência e a construção de identidades coletivas e diversas que possibilitou que mulheres pudessem - enquanto atores coletivos - afirmar sua autonomia, se mobilizar, tematizar questões e encampar lutas importantes por meio de diferentes repertórios de ação e interação com o Estado na busca por mudança sociais, políticas e culturais.

Considerando a existência de oportunidades políticas favoráveis à expressão de grupos sociais a partir da década de 1980 no Brasil, diante de um cenário de redemocratização, é possível afirmar que a criação de diversos órgãos públicos, políticas e programas governamentais voltados para promoção dos direitos das mulheres no país é certamente resultado da importância política das lutas feministas e dos movimentos de mulheres. A interação desses movimentos com o Estado, tendo em vista este contexto, se deu não só via contestação, pressão e interlocução em canais institucionais, como também pela própria participação de feministas e militantes nos organismos estatais, contribuindo para a visibilidade da importância da igualdade de gênero no país.

Ao longo dos últimos anos, fica evidente como as iniciativas relacionadas a gênero e às políticas para as mulheres estiveram presentes na agenda do governo federal, mais especificamente em um contexto político em que temas voltados à participação, inclusão social e a conquista da cidadania passaram a ganhar ênfase e serem priorizados, o que demonstra uma abertura à agenda reivindicatória dos movimentos de mulheres e feministas, e a tendência de transformação de demandas em pautas efetivas de ação governamental.

Tais fatos demonstram que a dimensão estratégica de ação do movimento feminista contemporâneo tenha tido sucesso não só no âmbito das relações sociais, como em termos institucionais e políticos, embasados por um sentido cultural diante da propagação do pensamento feminista e seu ideal de transformação social.

Considera-se que iniciativas formais que garantam a promoção dos direitos das mulheres são escolhas políticas, nem todos os âmbitos de governo adotam essa prática, nem todas as políticas e ações se pautam pela transversalidade de gênero visando à incorporação dessa perspectiva como proposta de intervenção no real. Apesar dos avanços e conquistas em âmbito nacional até meados de 2015, evidencia-se uma tematização crítica por parte dos movimentos feministas do contexto político atual de retrocessos e desconstruções em relação aos direitos e conquistas populares alcançadas, e assim, das possibilidades de ação diante deste contexto que estabelece um cenário não favorável de oportunidades políticas. As diferentes medidas que vêm sendo adotadas no país - sobretudo nos anos de 2016 e 2017, como a extinção de secretarias e ministérios às 
FEMINISMO E MOVIMENTOS DE MULHERES NO CONTEXTO BRASILEIRO:

A CONSTITUIÇÃO DE IDENTIDADES COLETIVAS E A BUSCA DE INCIDÊNCIA NAS POLÍTICAS PÚBLICAS

quais estavam vinculadas as políticas para as mulheres, por exemplo, cortes em orçamentos ou a deslegitimação progressiva das mulheres enquanto sujeitos políticos -, têm impacto substancial nas iniciativas e propostas de intervenções que dizem respeito à proteção e promoção de direitos conquistados até então, voltados a garantir a cidadania das mulheres, o que demonstra, para além da necessidade de continuidade das históricas lutas dos movimentos feministas, um desafio atual ainda maior a ser defrontado, demarcando, sobremaneira, a importância política das suas mobilizações e ações coletivas.

\section{Referências}

ABERS, Rebecca.; SERAFIM, Lizandra.; TATAGIBA, Luciana. Repertórios de Interação Estado-Sociedade em um Estado Heterogêneo: A Experiência na Era Lula. DADOS - Revista de Ciências Sociais, Rio de Janeiro, vol.57, no 2, 2014, p.325-357.

ADRIÃO, Karla G. et al. O movimento feminista brasileiro na virada do século XX: reflexões sobre sujeitos políticos na interface com as noções de democracia e autonomia. Estudos Feministas, Florianópolis, 19(3): 392, setdez, 2011.

ALONSO, Ângela. As teorias dos movimentos sociais: um balanço do debate. Lua Nova, São Paulo, n.76, p. 49-86. 2009.

AGUIAR, Neuma. Patriarcado, sociedade e patrimonialismo. Sociedade e estado, v. 15, n. 2, p. 303-330, 2000.

AVRITZER, Leonardo. Instituições participativas e desenho institucional: algumas considerações sobre a variação da participação no Brasil Democrático. Revista Opinião Pública, Campinas, vol. 14, n 1, 2008, pp. 43-64.

BANDEIRA, Lourdes M.; ALMEIDA, Tânia M.C. A transversalidade de gênero nas políticas públicas. Revista do Ceam, v. 2, n. 1, jan-jun. 2013.

BANDEIRA, Lourdes M.; MELO, Hildete P. de. Tempos e memórias do feminismo no Brasil. Presidência da República. Secretaria de Políticas para as Mulheres. Brasília: SPM, 2010.

BARSTED, Leila de A. L. Em busca do tempo perdido: mulher e políticas públicas no Brasil - 1983-1993. Revista Estudos Feministas, Rio de Janeiro, CIEC/ ECO/ UFRJ, v. 2, número especial, p.38-54, 1994.

BRASIL. Presidência da República. Secretaria de Políticas para as Mulheres (SPM). Plano Nacional de Políticas para as Mulheres 2013-2015. Brasília: Secretaria de Políticas para as Mulheres, 2013.

DINIZ, Simone D. Violência contra a mulher: estratégias e respostas do movimento feminista no Brasil (1980-2005). In: Vinte e cinco anos de respostas brasileiras em violência contra a mulher: Alcances e Limites DINIZ, Simone D.; SILVEIRA, Lenira P.; MIRIM, Liz A. (Org.) São Paulo: Coletivo Feminista Sexualidade e Saúde, 2006.

FARAH, Marta F.S. Políticas Públicas e gênero. In: Políticas públicas e igualdade de gênero/ Tatau Godinho (org). Maria Lúcia da Silveira (org). - São Paulo: Coordenadoria Especial da Mulher, 2004. (Cadernos da Coordenadoria Especial da Mulher, 8).

Gênero e políticas públicas. Revista Estudos Feministas. FGV - EAESP. Florianópolis, 12(1): 360, p.4771, jan-abr, 2004a.

FERES JUNIOR, João.; POGREBINSCHI, Thamy. Teoria política contemporânea: uma introdução. Rio de Janeiro: Elsevier, 2010.

FRASER, Nancy. Mapeando a imaginação feminista: da redistribuição ao reconhecimento e à representação. Estudos Feministas, Florianópolis, 15(2): 240, mai-ago/2007.

GARCÊZ, Regiane L. O. Teoria do Reconhecimento: uma teoria dos movimentos sociais?. II Simpósio Nacional sobre Democracia e Desigualdades. Anais do Il Simpósio Nacional sobre Democracia e Desigualdades. Brasília, 2014.

GOHN, Maria da Glória. Teoria dos movimentos sociais: paradigmas clássicos e contemporâneos. São Paulo: Loyola, 1997. 
HARAWAY, Donna. "Gênero" para um dicionário marxista: a política sexual de uma palavra. Cadernos Pagu (22), p.201-246, 2004

HEYWOOD, Andrew. Ideologias políticas: do feminismo ao multiculturalismo. Isabel de Assis R. Oliveira (revisão técnica). São Paulo: Ática, 2010.

MATOS, Marlise. A quarta onda feminista e o campo crítico-emancipatório das diferenças no Brasil: entre a destradicionalização social e o neoconservadorismo político. $38^{\circ}$ Encontro Anual da ANPOCS. Caxambu, out. 2014.

Gênero e sexualidade nas políticas públicas: o temor de retrocesso. Teoria e Debate. Edição 149, jun, 2016. Disponível em: <http://www.teoriaedebate.org.br/index.php?q=materias\%2Fsociedade\%2Fgeneroe-sexualidade-nas-politicas-publicas-o-temor-de-retrocesso> Acesso em 25 jul. 2016.

O movimento e a teoria feminista em sua nova onda: entre encontros e confrontos, seria possível reconstruir a teoria feminista a partir do sul global? Rev. Sociol. Polít., Curitiba, v. 18, n. 36, p. 67-92, jul. 2010.

MELUCCl, Alberto. A invenção do presente: movimentos sociais nas sociedades complexas. Tradução de Maria do Carmo Alves do Bomfim. - Petrópolis, RJ: Vozes, 2001.

Um objetivo para os movimentos sociais? Revista Lua Nova, n 17. CEDEC, São Paulo, 1989.

MIGUEL, Luis F.; BIROLI, Flávia. Teoria política feminista, hoje. In: Teoria política feminista: textos centrais. Luis Felipe Miguel e Flávia Biroli (organização) — Vinhedo, Editora Horizonte, 2013.

OGANDO, Ana Carolina. Da república sem mulheres à modernização patriarcal: origens e metamorfoses das relações de gênero no Brasil. 2012.302f. Tese (Doutorado em Ciência Política) - Faculdade de Filosofia e Ciências Humanas, Universidade Federal de Minas Gerais, 2012.

OKIN, Susan M. Gênero, o público e o privado. Estudos Feministas, Florianópolis, 16(2): 305-332, mai-ago, 2008.

PATEMAN, Carole. O contrato Sexual (1988). Tradução de Marta Avancini. São Paulo: Paz e Terra, 1993.

PINHEIRO, Marina B.; OGANDO, Ana Carolina. Os impactos dos Planos Nacionais de Políticas para as Mulheres nas políticas públicas no Brasil. In: I Simpósio Nacional sobre Democracia e Desigualdades, 2012, Brasília. Anais do I Simpósio Nacional sobre Democracia e Desigualdades, 2012.

PINTO, Céli R. J. Feminismo, história e poder. Rev. Sociol. Polít., Curitiba, v. 18, n. 36, p. 15-23, jun. 2010. O feminismo no Brasil: suas múltiplas faces. Fundação Perseu Abramo (Coleção Histórias do Povo Brasileiro). São Paulo, 2003.

PITANGUY, Jacqueline. Movimento de mulheres e políticas de gênero no Brasil. CEPAL, Governabilidad Democrática e Igualdad de Género en América Latina y el Caribe. Estudios Nacionales, noviembre de 2002. Disponível em: < http://www.cepal.org/mujer/proyectos/gobernabilidad/documentos/jpitanguy.pdf> Acesso em 20 jul. 2016

Mulheres, constituinte e constituição. In: Redistribuição, reconhecimento e representação: diálogos sobre a igualdade de gênero. Maria Aparecida Abreu (org.). Brasília: IPEA, 2011.

SAFFIOTI, Heleieth. Gênero, patriarcado, violência. São Paulo: Editora Fundação Perseu Abramo, 2004.

SARDENBERG, Cecília M.B.; COSTA, Ana A.A. Feminismo, feministas e movimentos sociais. In: Mulher e relações de gênero. Margarida L.R. Bradão e Maria Clara L. Bingemer (orgs.). Edições Loyola: São Paulo, 1994.

SARTI, Cynthia. Feminismo no Brasil: uma trajetória particular. Cad. Pesq. São Paulo. (64): 38-47, fev. 1988.

SCHUMAHER, Maria Aparecida.; VARGAS, Elisabeth. Lugar no governo: álibi ou conquista? Revista Estudos Feministas, vol. 1, n² 2, Rio de Janeiro, CIEC/ECO/UFRJ, 1993.

SCOTT, Joan. Gender: a useful category of historical analyses. Tradução: Christine Rufino Dabat e Maria Betânia Ávila. Gender and the politics of history. New York, Columbia University Press, 1989.

SILIPRANDI, Emma. Mulheres e agroecologia: transformando o campo, as florestas e as pessoas./ Emma Siliprandi. - Rio de Janeiro: Editora UFRJ, 2015. 352 p.

SILVA, Carmen; CAMURÇA, Silvia. Feminismo e movimentos de mulheres. Recife: Edições SOS Corpo, 2010. 
FEMINISMO E MOVIMENTOS DE MULHERES NO CONTEXTO BRASILEIRO:

A CONSTITUIÇÃO DE IDENTIDADES COLETIVAS E A BUSCA DE INCIDÊNCIA NAS POLÍTICAS PÚBLICAS

SILVA, Tomaz Tadeu da. A produção social da identidade e da diferença. In: SILVA, Tomaz Tadeu da. (org). Identidade e diferença. A perspectiva dos estudos culturais. 14 ed. Petrópolis: Vozes, 2014.

SOARES, Vera. Políticas públicas para igualdade: papel do Estado e diretrizes. In: Políticas públicas e igualdade de gênero/ Tatau Godinho (org). Maria Lúcia da Silveira (org). - São Paulo: Coordenadoria Especial da Mulher, 2004.

TEIXEIRA, Elenaldo. O local e o global: limites e desafios da participação cidadã. São Paulo: Cortez; Recife: Equip, 2001.

TELES, Maria Amélia de Almeida. Breve história do feminismo no Brasil. Ed. Brasiliense, 1993.

TIMOTEO, C.Q. As transformações do movimento feminista no Brasil e sua relação com a América Latina. $V$ Simpósio Internacional Lutas Sociais na América Latina. GEPAL, 2003.

YOUNG, Iris. Marion. Justice and the Politics of Difference. Princeton: Princeton, 1990. 